\title{
Osteopontin enhances donor-specific alloreactivity of human peripheral blood mononuclear cells
}

\author{
Beata Kaleta ${ }^{1, A-F} \odot$ \\ ${ }^{1}$ Department of Clinical Immunology, Medical University, Warsaw, Poland \\ A - Research concept and design, B - Collection and/or assembly of data, C - Data analysis and interpretation, \\ $D$ - Writing the article, $E$ - Critical revision of the article, $F$ - Final approval of article
}

Kaleta B. Osteopontin enhances donor-specific alloreactivity of human peripheral blood mononuclear cells. J Pre Clin Clin Res. 2019; 13(3): 106-109. doi: 10.26444/jpccr/112512

\begin{abstract}
Introduction. Graft-versus-host disease (GVHD) is a serious complication after allogeneic haematopoietic stem cell transplantation (HSCT). Osteopontin (OPN) is a pleiotropic glycoprotein, which plays a significant role in the regulation of biomineralization, wound healing, and cellular immunity. Numerous studies have demonstrated that elevated OPN levels are associated with the pathogenesis of multiple autoimmune and inflammatory conditions. However, its role in GVHD and transplant immunology is poorly understood.

Objective. The the aim of the study was to investigate the effects of OPN on human peripheral blood mononuclear cells (PBMCs) proliferation in a mixed lymphocyte reaction (MLR).

Materials and method. PBMCs were isolated from the venous blood of 20 participants. Cell proliferation was examined at the DNA synthesis level by measurements of $3 \mathrm{H}$-thymidine incorporation. Radioactivity was used to calculate the MLR stimulation index (SI). Cell viability was determined using the trypan blue exclusion method.

Results. OPN enhanced the proliferative response of human alloactivated PBMCs in MLR. Statistically significant results were observed for OPN of 100, 200, 300 and $400 \mathrm{ng} / \mathrm{mL}(P=0.013, P=0.009 ; P=0.003$ and $P<0.001$, respectively). Moreover, OPN increased SI in a dose-dependent way $(P=0.011, P=0.007 ; P=0.002$ and $P<0.001$, respectively). In addition, this protein did not affect cells viability.

Conclusions. The results confirm the assumption that OPN may affect the outcome after HSCT; however, future investigation is needed to verify whether it may serve as a valuable predictive and prognostic marker of GVHD.
\end{abstract}

\section{Key words}

osteopontin, graft versus host disease, mixed lymphocyte reaction, alloreactivity.

\section{INTRODUCTION}

Graft-versus-host disease (GVHD) is an immune-mediated complication after allogeneic haematopoietic stem cell transplantation (HSCT), which affects up to $60 \%$ of patients and is a major cause of their mortality [1]. GVHD occurs when donor $\mathrm{T}$ lymphocytes, in response to recipient mismatched Human Leukocyte Antigens (HLA), differentiate into alloreactive $\mathrm{T}$ cells, which migrate to the skin, liver and gastrointestinal tract, causing tissue damage [2]. Previous studies demonstrated that pro-inflammatory cytokines and chemokines are critical for GVHD pathogenesis and progression $[1,3]$.

Osteopontin (OPN) is a pleiotropic glycoprotein, produced by various cells, including bone, skin, smooth muscle, intestinal epithelial cells, T lymphocytes, natural killer cells, macrophages, neutrophils, dendritic cells, and many others $[4,5]$. Numerous studies showed that OPN plays a significant role in the regulation of biomineralization, wound healing, and cellular immunity [5-7]. In addition, elevated OPN levels have been found in multiple autoimmune diseases, cancer, diabetes, infections and coronary artery disease [8-14]. Moreover, it was demonstrated that OPN concentration in

Addres for correspondence: Beata Kaleta, Department of Clinical Immunology, Medical University, Warsaw, Poland

E-mail: kaletabeata1@gmail.com

Received: 03.07.2019; accepted: 18.09.2019; first published: 20.09.2019 the plasma and urine of patients after kidney transplantation correlates with acute cellular renal allograft rejection [15]. However, the effects of OPN on the proliferation of human alloantigen-activated lymphocytes have not been examined to-date, and its role in GVHD is not fully understood.

\section{OBJECTIVES}

The aim of the study was to investigate the influence of OPN on human peripheral blood mononuclear cells (PBMCs) proliferation in a mixed lymphocyte reaction (MLR). MLR is one of the predictive tests before HSCT, used for assessing the GVHD risk. The stimulation index (SI) is one of the formulas of the MLR, used for evaluation of matching between donor and recipient [16].

\section{MATERIALS AND METHOD}

Isolation of peripheral blood mononuclear cells and mixed lymphocyte reaction. 20 healthy blood donors (10 women and 10 men, mean age 37 years \pm 9 ) participated in the study. Brief characteristics of the study group are presented in Table 1. PBMCs were isolated from heparinized blood by centrifugation on Histopaque-1077 (Sigma, St. Louis, USA) and resuspended in RPMI 1640 medium (Gibco, Darmstadt, 
Table 1. General characteristics of participants

\begin{tabular}{lccc}
\hline & Male & Female & Total \\
\hline Number & 10 & 10 & 20 \\
\hline Range of age (mean) & $28-43(36)$ & $31-46(38)$ & $28-46(37)$ \\
\hline
\end{tabular}

Germany), supplemented with $2 \mathrm{mM} \mathrm{L}$-glutamine (Sigma, St. Louis, USA), antibiotic-antimycotic solution (1.5\% penicillin-streptomycin-amfoterycin, Invitrogen, Carlsbad, USA), $\beta$-mercaptoethanol (Sigma, St. Louis, USA), 0.23\% Hepes (Sigma, St. Louis, USA) and 10\% foetal bovine serum (FBS, Gibco Darmstadt, Germany). PBMCs were divided into two groups: 1) responding cells and 2) stimulatory cells, which were inactivated by gamma-irradiation for $90 \mathrm{~min}$. For the one-way MLR, $2 \times 10^{5} \mathrm{PBMCs}\left(1 \times 10^{5}\right.$ cells/well from the first donor and $1 \times 10^{5}$ cells/well from the second donor) were co-cultured with OPN at concentrations of 10, 20,50, $100,200,300$ and $400 \mathrm{ng} / \mathrm{mL}$ in the following combinations: XYir and YXir (X - first donor's responding PBMCs, Yir irradiated second donor's stimulatory PBMCs, Y - second donor's responding PBMCs, Xir - irradiated first donor's stimlatory PBMCs).

For the experiments, human recombinant endotoxin-free OPN was used (R\&D Systems, Minneapolis, USA). Control cultures contained equivalent volumes of medium. After incubation for $72 \mathrm{~h}$ (at $37^{\circ} \mathrm{C}$ in a humidified atmosphere with $5 \% \mathrm{CO}_{2}$.), the dividing cells were labelled with $1 \mu \mathrm{Ci} /$ well of ${ }^{3} \mathrm{H}$-thymidine (113 Ci/nmol, NEN, Boston, USA) for the last $18 \mathrm{~h}$ of the incubation and harvested. Radiocativity ('counts per minute', cpm) was quantified in a scintillation counter (Wallac PerkinElmer, Boston, USA). Radioactivity was used to calculate the MLR stimulation index: $\mathrm{SI}=$ (average $\mathrm{cpm}$ of the mixed responder and stimulator - average cpm of the responder)/average cpm of the responder. All experiments were performed in triplicates.

Cell viability assay. PBMCs viability was examined using trypan blue staining. After 3 days of culture, PBMCs were collected and stained with $0.4 \%$ trypan blue. The number of total and dead cells was counted using a haemocytometer. Values were expressed as a percentage of control culture viability $(100 \%)$.

Statistical analysis. All analyses were performed with Statistica version 13.0. Results were expressed as mean \pm standard deviation (SD). After testing all the data for normality (Shapiro-Wilk test), one-way ANOVA was used to compare values obtained with or without OPN treatment. A probability value of $\mathrm{P}<0.05$ with a $95 \%$ confidence interval was considered to indicate a statistically significant difference.

The study was approved by the Ethics Committee of Medical University of Warsaw (No. KB/164/2017) and all subjects provided written informed consent. The procedures followed were in accordance with the Helsinki Declaration of 1975 , as revised in 2000 .

\section{RESULTS}

In the present preliminary study, the proliferation was assessed of alloantigen-activated PBMCs in the presence of different concentrations of OPN. It was demonstrated that OPN enhances the proliferative response in MLR

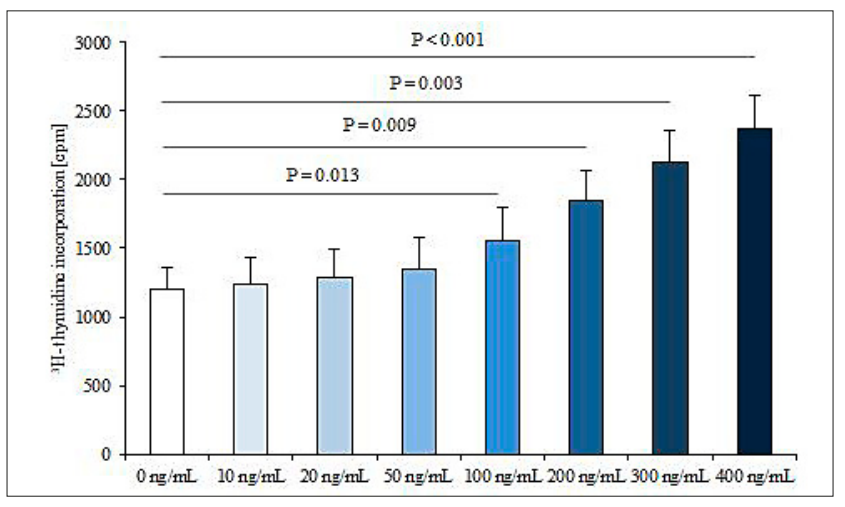

Figure 1. Effects of osteopontin (OPN) on allogenic peripheral blood mononuclear cells (PBMCs) proliferation in one-way mixed lymphocyte reaction (MLR). The results are presented as mean \pm standard deviation (SD) of 20 experiments performed in triplicates

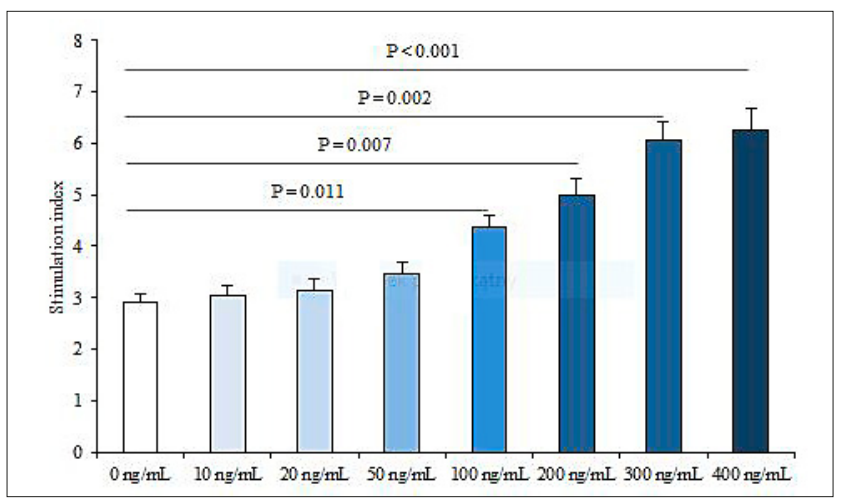

Figure 2. Effects of osteopontin (OPN) on stimulation index (SI) of allogeneic mixed lymphocyte reaction (MLR). Data are expressed as the mean $\mathrm{SI} \pm$ standard deviation (SD) of 20 experiments performed in triplicates

performed with human allogenic PBMCs. MLR enhancement was induced by OPN in all tested concentrations; however, statistically significant results were observed for OPN of $100,200,300$ and $400 \mathrm{ng} / \mathrm{mL}(\mathrm{P}=0.013, \mathrm{P}=0.009, \mathrm{P}=0.003$ and $\mathrm{P}<0.001$, respectively) (Fig. 1). Moreover, evaluation of the MLR revealed that the OPN in concentations of 100 , 200, 300 and $400 \mathrm{ng} / \mathrm{mL}$ increased SI in a dose-dependent way $(\mathrm{P}=0.011 ; \mathrm{P}=0.007 ; \mathrm{P}=0.002$ and $\mathrm{P}<0.001$, respectively) (Fig. 2).

The trypan blue exclusion test showed that cell viability did not significantly differ between the OPN-co-cultured variants (in all tested concentrations) and the control group. The mean percentage of viable cells was $96.6 \% \pm 0.9 \%$ (range: $94 \%$ - 98\%) (data not shown).

\section{DISCUSSION}

The study demonstrated that OPN dose-dependently enhances the proliferative response in MLR performed with allogeneic PBMCs. The results confirm the assumption that this glycoprotein may be a factor which affects the outcome after HSCT.

As mentioned before, OPN is expressed by numerous immune cells $[4,5]$. Multiple studies have revealed that this protein plays an important role in immunomodulation. It was shown that OPN regulates migration and activation of macrophages, as well as synthesis of nitric oxide and proinflammatory cytokines $[5,6]$. Moreover, OPN is a 
chemoattractant for neutrophils, regulates dendritic cells maturation and migration, and affects immunoglobulin production by B cells [5-9]. Recent evidence indicates that OPN promotes the T hepler (Th) 1 and Th17 response and regulates the Th1/Th2 balance [8-10].

Although numerous studies revealed the role of OPN in the regulation of immunity and inflammation, it is not fully known whether OPN participates in the pathogenesis and course of GVHD. Two studies conducted to evaluate the role of OPN in mouse models of GVHD gave opposite results. Kawakami et al. [17] showed that in OPN knockout (KO) mice, the gastrointestinal GVHD score was elevated. Moreover, the infiltration of $\mathrm{CD}^{+}$and $\mathrm{CD}^{+} \mathrm{T}$ cells in the colon and small intestine of GVHD mice was increased when the donor was OPN-KO. In addition, the expression of pro-inflammatory cytokines (interleukin (IL)-17A, IL18 , interferon (IFN) $-\gamma$, tumour necrosis factor (TNF)- $\alpha$ ), as well as the number of apoptic epithelial cells was higher in donor cells lacking OPN. These findings suggest that OPN plays a significant role in the GVHD attenuation. However, different results were obtained in a study of Zhao et al. [18] who showed that in mice with GVHD, OPN concentration was elevated and associated with higher migration and infiltration of donor $\mathrm{CD}^{+} \mathrm{T}$ cells into recipient organs. It was also demonstrated that during GVHD, anti-OPN treatment supressed donors $\mathrm{CD} 8^{+} \mathrm{T}$ cells viability and activation. This suggests that OPN plays a role in GVHD and thus may serve as a potential target in disease prevention. The results of the current study likewise confirm the hypothesis that OPN may be associated with GVHD pathogenesis; however, the exact mechanisms are not fully elucidated.

Previous reports demonstrated that OPN regulates $\mathrm{T}$ cells survival and activation. It was shown that OPN via interactions with CD44 receptor activates intracellular phosphatidylinositol 3-kinase (PI3K) and Akt/protein kinase $\mathrm{B}$ pathway, which is important in regulating the cell cycle $[18,19]$. Moreover, binding OPN to $\alpha \mathrm{V}$ integrin induces PI3K/Akt-dependent nuclear factor-kB activation [20]. In addition, OPN participates in the recruitment of $\mathrm{CD}^{+} \mathrm{T}$ cells $[17,18]$, as well as regulating cell polarization [18]. Despite this knowledge, further investigations are necessary to fully understood the role of OPN in GVHD pathogeneis and progression.

A few recent studies have evaluated OPN in patients after transplantation. Alchi et al. [15] found that OPN mRNA and protein expression in renal transplant biopsies from patients with acute allograft rejection (AAR) was higher than in non-rejection patients and healthy controls. Moreover, the expression correlated with the degree of intestinal inflammation and monocyte infiltration. In another study, higher levels of OPN in serum of patients after kidney transplantation were associated with the lower probability of rejection-free survival [21]. Rouschop et al. [22] analyzed OPN level and its CD44 receptor in renal biopsies and in plasma of patients with ARR. It was showed that during ARR, OPN and CD44 were upregulated in the renal allograft. However, no differences were found between the different pathologic grades of rejection and OPN/CD44 expression. Similar results were obtained in a study by Ouyang et al. [23], conducted in a rat renal transplantation model. It was found that during the early stage of $A R$, the expression of OPN mRNA was upregulated.

\section{CONCLUSIONS}

To the best of the author's knowledge, the presented study is the first to be conducted in humans and suggests that OPN may contribute to GVHD pathogenesis and progression. The study demonstrated that OPN in a dose-dependent way enhances the proliferation of alloactivated cells. Thus, it is suggest that OPN may be useful in predicting GVHD in HSCT patients. It may also lead to the hypothesis that in GVHD patients, anti-OPN treatment may be used for disease treantment. However, future investigation is needed to verify if OPN may serve as avaluable predictive and prognostic marker of GVHD after HSCT.

\section{Conflicts of Interest}

The authors declare no conflict of interest.

\section{REFERENCES}

1. Ferrara JL, Levine JE, Reddy P, Holler E. Graft-versus-host disease. Lancet. 2009; 373(9674): 1550-1561. https://doi.org/10.1016/S0140 6736(09)60237-3.

2. Petersdorf EW. Role of major histocompatibility complex variation in graft-versus-host disease after hematopoietic cell transplantation. F1000Res. 2017; 6: 617. https://doi.org/10.12688/f1000research.10990.1.

3. Moreno DF, Cid J. Graft-versus-host disease. Med Clin (Barc). 2019; 152(1): 22-28. https://doi.org/10.1016/j.medcli.2018.07.012.

4. Fisher LW, Torchia DA, Fohr B, Young MF, Fedarko NS. Flexible structures of SIBLING proteins, bone sialoprotein, and osteopontin. Biochem Biophys Res Commun. 2001; 280(2): 460-465. https://doi. org/10.1006/bbrc.2000.4146.

5. Icer MA, Gezmen-Karadag M. The multiple functions and mechanisms of osteopontin. Clin Biochem. 2018; 59: 17-24. https://doi.org/10.1016/j. clinbiochem.2018.07.003.

6. Subraman V, Thiyagarajan M, Malathi N, Rajan ST. OPN - Revisited J Clin Diagn Res. 2015; 9(6): ZE10-ZE13. https://doi.org/10.7860/ JCDR/2015/12872.6111.

7. Rittling SR, Singh R. Osteopontin in Immune-mediated Diseases. J Dent Res. 2015; 94(12): 1638-1645. https://doi.org/10.1177/0022034515605270.

8. Clemente N, Raineri D, Cappellano G, Boggio E, Favero F, Soluri $\mathrm{MF}$ et al. Osteopontin Bridging Innate and Adaptive Immunity in Autoimmune Diseases. J Immunol Res. 2016; 7675437. https://doi. org/10.1155/2016/7675437.

9. Lok ZSY, Lyle AN. Osteopontin in Vascular Disease. Arterioscler Thromb Vasc Biol. 2019; 39(4): 613-622. https://doi.org/10.1161/ ATVBAHA.118.311577.

10. Uede T. Osteopontin, intrinsic tissue regulator of intractable inflammatory diseases. Pathol Int. 2011; 61(5): 265-280. https://doi. org/10.1111/j.1440-1827.2011.02649.x.

11. Wen Y, Jeong S, Xia Q, Kong X. Role of Osteopontin in Liver Diseases. Int J Biol Sci. 2016; 12(9): 1121-1128. https://doi.org/10.7150/ijbs.16445

12. Komine-Aizawa S, Masuda H, Mazaki T, Shiono M, Hayakawa S, Takayama T. Plasma osteopontin predicts inflammatory bowel disease activities. Int Surg. 2015; 100(1): 38-43. https://doi.org/10.9738/ INTSURG-D-13-00160.1.

13. Konno S, Kurokawa M, Uede T, Nishimura M, Huang SK. Role of osteopontin, a multifunctional protein, in allergy and asthma. Clin Exp Allergy. 2011; 41(10): 1360-1366. https://doi.org/10.1111/j.13652222.2011.03775.x.

14. Zhu Q, Luo X, Zhang J, Liu Y, Luo H, Huang Q et al. Osteopontin as a Potential Therapeutic Target for Ischemic Stroke. Curr Drug Deliv. 2017; 14(6): 766-772. https://doi.org/10.2174/1567201814666161116162148.

15. Alchi B, Nishi S, Kondo D, Kaneko Y, Matsuki A, Imai N et al. Osteopontin expression in acute renal allograft rejection. Kidney Int. 2005; 67(3): 886-896. https://doi.org/10.1111/j.1523-1755.2005.00153.x.

16. Sayılan Şen H, Kılıçaslan Ayna T, Şentürk Çiftçi H, Kalayoğlu Beşışık $\mathrm{S}$, Onal EA, Akçay A et al. The predictive value of stimulation index calculated by modified mixed lymphocyte culture in the detection of GVHD following hematopoietic stem cell transplantation. Turk J Haematol. 2010; 27(4): 263-268. https://doi.org/10.5152/tjh.2010.48.

17. Kawakami K, Minami N, Matsuura M, Iida T, Toyonaga T, Nagaishi K et al. Osteopontin attenuates acute gastrointestinal graft-versus-host 
disease by preventing apoptosis of intestinal epithelial cells. Biochem Biophys Res Commun. 2017; 485(2): 468-475. https://doi.org/10.1016/j. bbrc.2017.02.047.

18. Zhao F, Zhang Y, Wang H, Jin M, He S, Shi Y et al. Blockade of osteopontin reduces alloreactive CD8+ T cell-mediated graft-versushost disease. Blood. 2011; 117(5): 1723-1733. https://doi.org/10.1182/ blood-2010-04-281659.

19. Lin YH, Yang-Yen HF. The osteopontin-Cd44 survival signal involves activation of the phosphatidylinositol 3-kinase/Akt signaling pathway. J Biol Chem. 2001; 276(49): 46024-46030. https://doi.org/10.1074/jbc. M105132200.

20. Yu X, Zheng Y, Zhu X, Gao X, Wang C, Sheng Y et al. Osteopontin promotes hepatocellular carcinoma progression via the PI3K/AKT/
Twist signaling pathway. Oncol Lett. 2018; 16(4): 5299-5308. https:// doi.org/10.3892/ol.2018.9281

21. Jin ZK, Tian PX, Wang XZ, Xue WJ, Ding XM, Zheng J et al. Kidney injury molecule-1 and osteopontin: new markers for prediction of early kidney transplant rejection. Mol Immunol. 2013; 54 (3-4): 457-464. https://doi.org/10.1016/j.molimm.2013.01.013.

22. Rouschop KM, Roelofs JJ, Sylva M, Rowshani AT, Ten Berge IJ, Weening $\mathrm{JJ}$ et al. Renal expression of CD44 correlates with acute renal allograft rejection. Kidney Int. 2006; 70(6): 1127-1134. https://doi.org/10.1038/ sj.ki.5001711.

23. Ouyang J, He J, Fan YS, Fan CB, Sun HY, Wen DG. [Expressions of interleukin-15 and osteopontin mRNA in early stage of acute rejection of renal allograft in rats]. Article in Chinese. Zhonghua Yi Xue Za Zhi. 2010; 90(10): 698-702. 